\title{
A VORTEX DROP STRUCTURE AS DEAERATION SYSTEM FOR A SUBMARINE OUTFALL PIPELINE
}

\author{
Rolando García, PRDW, rgarcia@prdw.com
}

\section{INTRODUCTION}

Use of submarine outfall pipelines became more common since World Bank Group issued a new guideline for maximum emissions levels for thermal power plants in 1998 (van Dijk, 2005). The more restrictive levels for temperature increase at the receiving water, requires outfall systems to conduct the water down to greater depths to achieve the required dilution standard. However, air entrainment control into outfall pipes could be challenging, especially for discharges with high flowrates for which conventional deaeration chambers become too large.

The problem could turn more difficult in coastal shelf areas at seismic zones, where the hydraulic height of the incoming flow must be effectively controlled and the design not only has to pursue hydraulic objectives but also stability requirements for these massive structures subjected to relevant seismic thrusts.

A vortex drop structure was designed for the cooling water discharge system of a thermal power plant in Mejillones Bay, Chile. The structure addresses the elevation difference between the return flow pipe and the ocean outfall pipelines while adhering to the spatial restrictions at the project site. Energy dissipation as well as limitation of air entrainment into the outfall pipelines were critical design considerations.

Tests where done on a 1:12.5 scale (Froude) physical model. Prototype structure is under construction. Operation is planned to start on mid-2018.

\section{VORTEX DROP STRUCTURE}

A variable section vortex shaft and a tangential inlet ramp based on Brooks \& Blackmer (1962) was considered and adapted to the project requirements following design recommendations by Hager (1990). Use is made of USBR (1978) guidelines for the design of the stilling basin chamber which controls the upstream flow with a velocity of $6 \mathrm{~m} / \mathrm{s}$. The vortex shaft comprises three sections: a cylindrical upper section, a conical section and a straight cylinder section. The shaft discharges into an open atmosphere cylindrical chamber (vortex chamber), as shown in Figure 1. Water is then conducted by a free surface flow tunnel into a discharge chamber from which two outfall pipelines start. Main design parameters and prototype dimensions are provided in Table 1.

\section{PHYSICAL MODEL AND FINDINGS}

A physical model study was conducted at Instituto Nacional de Hidraulica de Chile (INH) to validate the design of the discharge system. Results showed that the stilling basin chamber provide suitable inlet conditions for the vortex ramp. The submerged shaft length into the vortex chamber was examined for air entrainment control. The vortex drop structure effectively reduces air entrainment into the flow and the remaining air can be gently removed along the downstream elements of the discharge system, which was verified to operate satisfactorily for the full range of operational conditions: tidal levels, flowrates from $0.5 \mathrm{Q}_{\mathrm{d}}$ up to $1.1 \mathrm{Q}_{\mathrm{d}}$, and plant start up and shut down.
Table 1. Design parameters and prototype dimensions of the discharge system.

\begin{tabular}{lc}
\hline \multicolumn{1}{c}{ Parameter } & Value \\
\hline Model scale (Froude) & $1: 12.5$ \\
\hline Design flow rate $\left(Q_{d}\right)$ & $11.7 \mathrm{~m}^{3} / \mathrm{s}$ \\
\hline Inlet pipe elevation & $+18.33 \mathrm{~m} \mathrm{LAT}$ \\
\hline Inlet flow velocity & $6.1 \mathrm{~m} / \mathrm{s}$ \\
\hline Outlet pipe diameter $(x 2)$ & $1.80 \mathrm{~m}$ \\
\hline Outlet pipe elevation & $-2.20 \mathrm{~m} \mathrm{LAT}$ \\
\hline Vortex shaft diameter $($ top $)$ & $3.60 \mathrm{~m}$ \\
\hline Vortex shaft diameter $(\mathrm{b})$ & $2.00 \mathrm{~m}$ \\
\hline
\end{tabular}
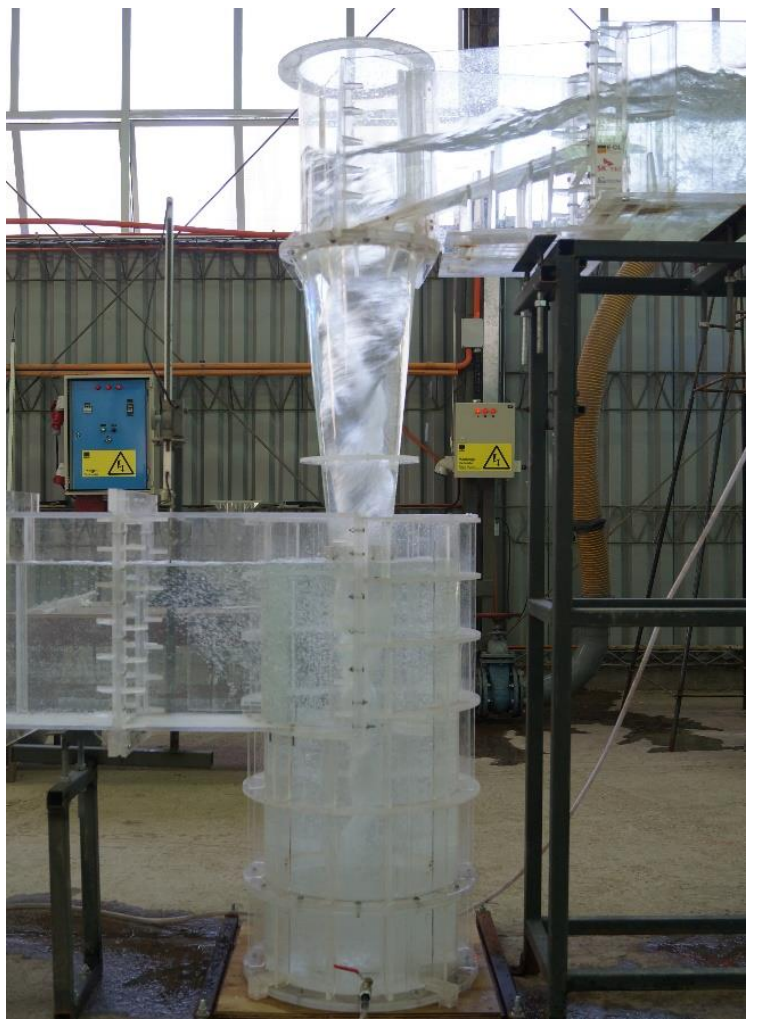

\section{REFERENECES}

Brooks, N. H. \& Blackmer, W. H., (1962). Last update 2012. Vortex Energy Dissipator for San Diego Outfall; Laboratory Investigations - Caltech Authors, [Online]. Available: http://resolver.caltech.edu/CaltechKHR:KH-R5.

Hager, W. H. (1990). Vortex Drop Inlet for Supercritical Approaching Flow. Journal of Hydraulic Engineering, 116, 8, 1048-1054.

United States Department of Interior Bureau of Reclamation, (1978). Engineering Monograph No. 25, Hydraulic Design of Stilling Basins and Energy Dissipators, [Online]. Available: http://www.usbr.gov/tsc/hydlab/pubs/EM/EM25.pdf.

V.N. van Dijk, (2005). Design of a cooling water outfall system. Master's Thesis. TU Delft. 